\title{
EL ORIGEN DEL OLIVO Y LA ANTROPIZACIÓN DEL ENTORNO DE CÁSTULO A PARTIR DE LA ANTRACOLOGÍA
}

\section{THE ORIGIN OF THE OLIVE TREE AND THE ANTHROPIZATION OF THE CASTULO ENVIRONMENT FROM ANTHRACOLOGY}

\author{
MARÍA OLIVA RODRÍGUEZ-ARIZA \\ Instituto Universitario de Investigación en Arqueología Ibérica-Universidad de Jaén. Edif. C6, Campus de las lagunillas s/n, 23071 Jaén. \\ Correo-e: moliva@ujaen.es (D) https://orcid.org/0000-0002-5983-6051 \\ ResearcherID: https://publons.com/researcher/AAR-5723-2020
}

Resumen: A través del estudio antracológico de Cástulo se observa un importante cambio cualitativo de las formaciones vegetales entre el periodo ibérico y el mundo romano. De un entorno donde predomina una vegetación de encinar se pasa a un espacio donde los cultivos arbóreos, principalmente el olivar, dominan el territorio. Esta transformación se produce como consecuencia de una nueva organización económica y de ordenamiento social y político que produce una reestructuración del entorno de Castulo, con la introducción del cultivo del olivo alrededor del cambio de era. Estos datos confirman que la Alta Andalucía no fue una zona secundaria en la producción de aceite, sino que pudo ser un foco de desarrollo de este cultivo a partir de mediados del siglo I a.C.

Palabras claves: antracología; ibérico; romano; Cástulo; arboricultura; olivo.

\section{INTRODUCCIÓN}

Los análisis antracológicos han sido usados normalmente para conocer la flora y la composición de las comunidades vegetales locales y regionales del pasado. Los análisis antracológicos clásicos en la región mediterránea se han centrado en la creación de una secuencia paleoambiental y en establecer una metodología para la correcta interpretación ecológica de los carbones de
Abstract: Through the charcoal analysis of remains from Castulo (S Spain), a major qualitative change in plant formations is detected between the Iberian and Roman periods. An environment dominated by holm oak vegetation shifts to a setting where tree crops, mainly olive groves, dominate the territory. This transformation occurs as a result of a new economic system and a social as well as political order that involves a restructuring of the Castulo environment, with the introduction of olive cultivation around the change of era. These data confirm that Alta Andalucía was not a secondary area in oil production, but could have been a focus for the development of this crop from the middle of the 1st century BC onwards.

Keywords: Anthracology; Iberian period; Roman period; Castulo; Olive-tree; Arboriculture.

origen antrópico (por ejemplo, Chabal 1992, Figueiral 1993, Badal et al. 1994, Vernet 1997).

Con más lentitud se van desarrollando estudios que inciden en el uso y la gestión de los recursos leñosos por parte de las comunidades prehistóricas, protohistóricas o antiguas (Rodríguez-Ariza 1989-90 y 2017, Figueiral 1996, Duque 2004, García y Grau 2005, Marston 2009, Rodríguez-Ariza y Montes 2010, Rubiales et al. 2011, Vila y Piqué, 2012, Vila 2018). Este hecho se produce 
por las propias características de las excavaciones arqueológicas realizadas, generalmente circunscritas a una pequeña área o sondeo, que impiden conocer diferentes contextos dentro de un mismo asentamiento y, también, por las limitaciones del propio carbón o madera, material natural y antrópico a la vez, que impide en muchas ocasiones conocer la procedencia y funcionalidad de las muestras estudiadas.

Este trabajo se centra en uno de los principales asentamientos excavados del Sur de la península, Cástulo, y que cuenta con una larga secuencia que va desde la Edad del Bronce Final (templo de La Muela) a la Edad Moderna (ermita de Santa Eufemia). Desde el inicio de las nuevas campañas de excavación en 2011 se ha prestado especial atención al conocimiento del marco paleoambiental del sitio arqueológico (Sánchez et al. 2020). Este es necesario para explicar la evolución y cambio en la sociedad de Cástulo a lo largo de los siglos. En este sentido, una de las principales cuestiones a conocer es la estrategia de explotación económica del entorno de Cástulo, prestando atención al desarrollo de la agricultura y la gestión forestal a lo largo de las distintas etapas históricas. Para ello, además de la recuperación de semillas y carbones de forma manual, se aplicó un muestreo sistemático de recogida de sedimentos en los diversos espacios y fases excavadas (siglos VIII a.C. al siglo IV d.C.) con la intención de recuperar restos vegetales y otros ecofactos para su posterior estudio (Tudela et al. 2014).

\section{CONTEXTO ARQUEOLÓGICO Y ECOLOGICO}

\subsection{El yacimiento arqueológico de Cástulo}

La Zona Arqueológica de Cástulo se sitúa a unos $7 \mathrm{~km}$ de la ciudad de Linares en la margen derecha del río Guadalimar, que surca esta parte de la Campiña de Jaén en dirección noreste-suroeste, unos kilómetros antes de su encuentro con el río Guadalquivir (fig. 1).

En el entorno del yacimiento arqueológico de Cástulo se ha documentado una secuencia histórica que va desde la Prehistoria a la Edad Moderna (Tornero 1998), aunque los primeros asentamientos estables se fechan a partir del siglo VIII a.C. El apogeo de Cástulo se produce a partir de época ibérica cuando se convierte en un importante oppidum, al que se superpone una extensa ciudad romana con un recinto amurallado de unas 50 ha. Su ubicación en la cabecera del valle del Guadalquivir le confiere una importante posición estratégica en el control de gran parte del sur de la península ibérica durante la Antigüedad (Fig. 1).

Cástulo tiene una importante tradición de estudio y recuperación de restos arqueológicos mantenida durante el siglo XX con los trabajos liderados por José María Blázquez (Blázquez 1975, 1979, 1981, Blázquez et al. 1984, 1985, Blázquez y García-Gelabert 1992, 1994). Ya en el siglo XXI, y a partir del año 2011, la actividad en la zona arqueológica se reactivó con los proyectos Forum MMX y Siglo XXI en Cástulo, dirigidos ambos por Marcelo Castro (Castro 2015). De las campañas de excavación realizadas entre 2011 y 2015 provienen las muestras estudiadas (Pérez 2014, Castro 2015, Ceprián et al. 2016, Soto et al. 2018). Estas excavaciones se centraron en varias zonas de la ciudad que, para facilitar su identificación, se han denominado áreas (de la 1 a la 4; fig. 2).

- El Área 1. Este espacio se localiza junto a las excavaciones realizadas por Blázquez en los años 70 del siglo pasado identificadas como "La Villa del Olivar". Los trabajos en este espacio perseguían la definición estructural, funcional y estratigráfica de las edificaciones existentes y contrastar la hipotética identificación de este gran edificio con un $m a-$ cellum, o con alguna otra edificación localizada en el foro de la ciudad romana de Cástulo.

- El Área 2. En esta zona localizada hacia el suroeste del Área 1, la excavación iba dirigida a obtener los registros estratigráficos existentes, con el fin de evaluar la diacronía ocupacional, así como a realizar una aproximación a los contextos espaciales, funcionales y estructurales existentes. Estos sondeos permitieron el registro parcial de un gran edificio altoimperial, cuya caracterización ha orientado los trabajos en curso.

- El Área 3. Situada al noreste del asentamiento, es la zona donde actualmente se puede visualizar la muralla ibérica y donde se han excavado varios niveles de habitación de época ibérica.

- El Área 4. En esta zona, situada al noroeste del asentamiento, se ha documentado una gran estructura que, en su primera fase de uso, se identifica como una torre datada a finales del S. III a.C. Una vez que Roma consolida su poder, la superficie de la torre es reutilizada como santuario (Soto et al. 2018).

\subsection{Situación biogeográfica actual}

La vegetación natural del entorno de Cástulo es muy escasa al estar el territorio ocupado mayormente por el olivar y el cultivo de cereales, quedando relegada 

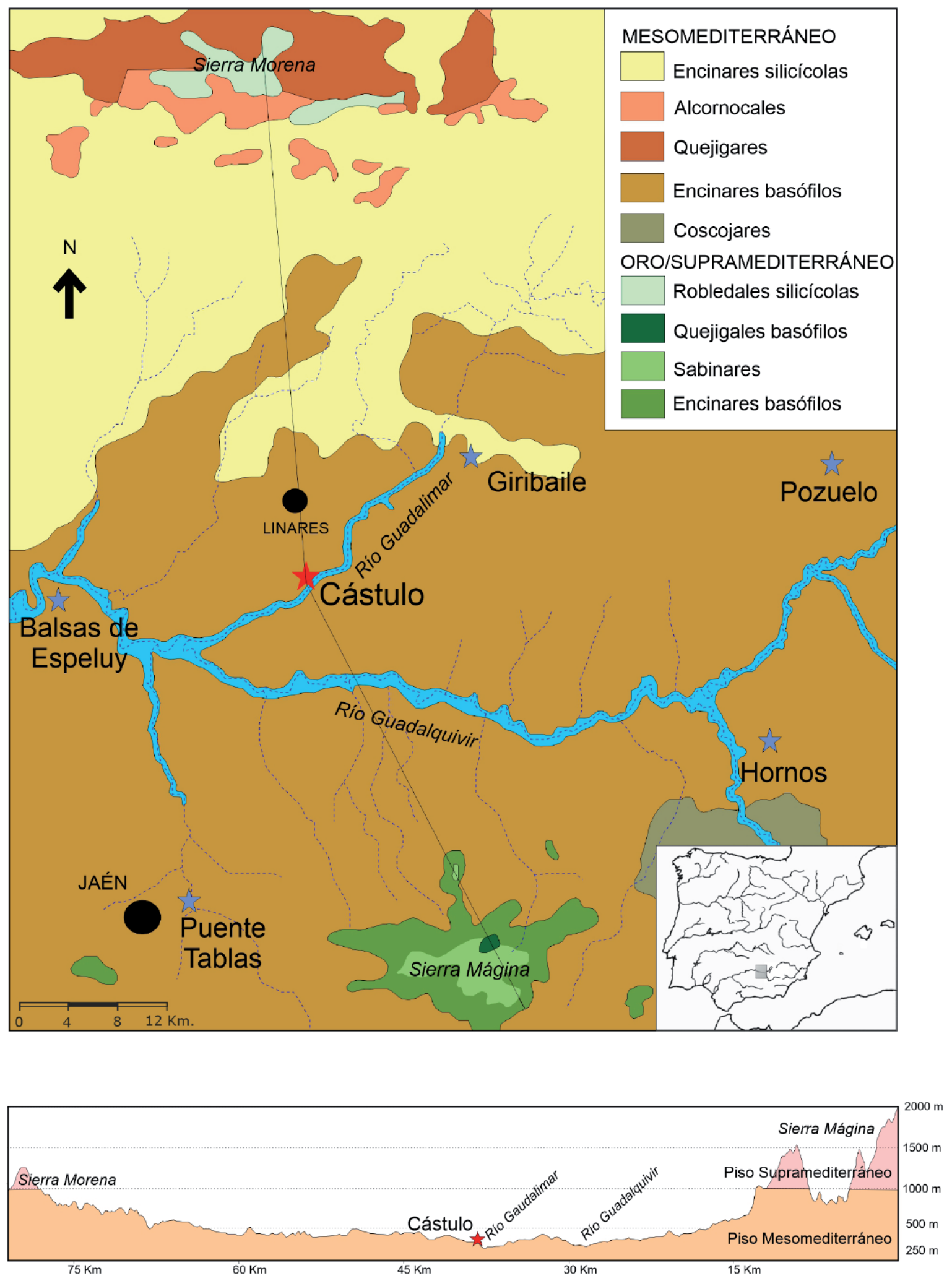

Figura 1. Mapa de series de vegetación (a partir de Rivas Martínez 1987) y corte topográfico con la localización de Cástulo dentro del alto Guadalquivir. 


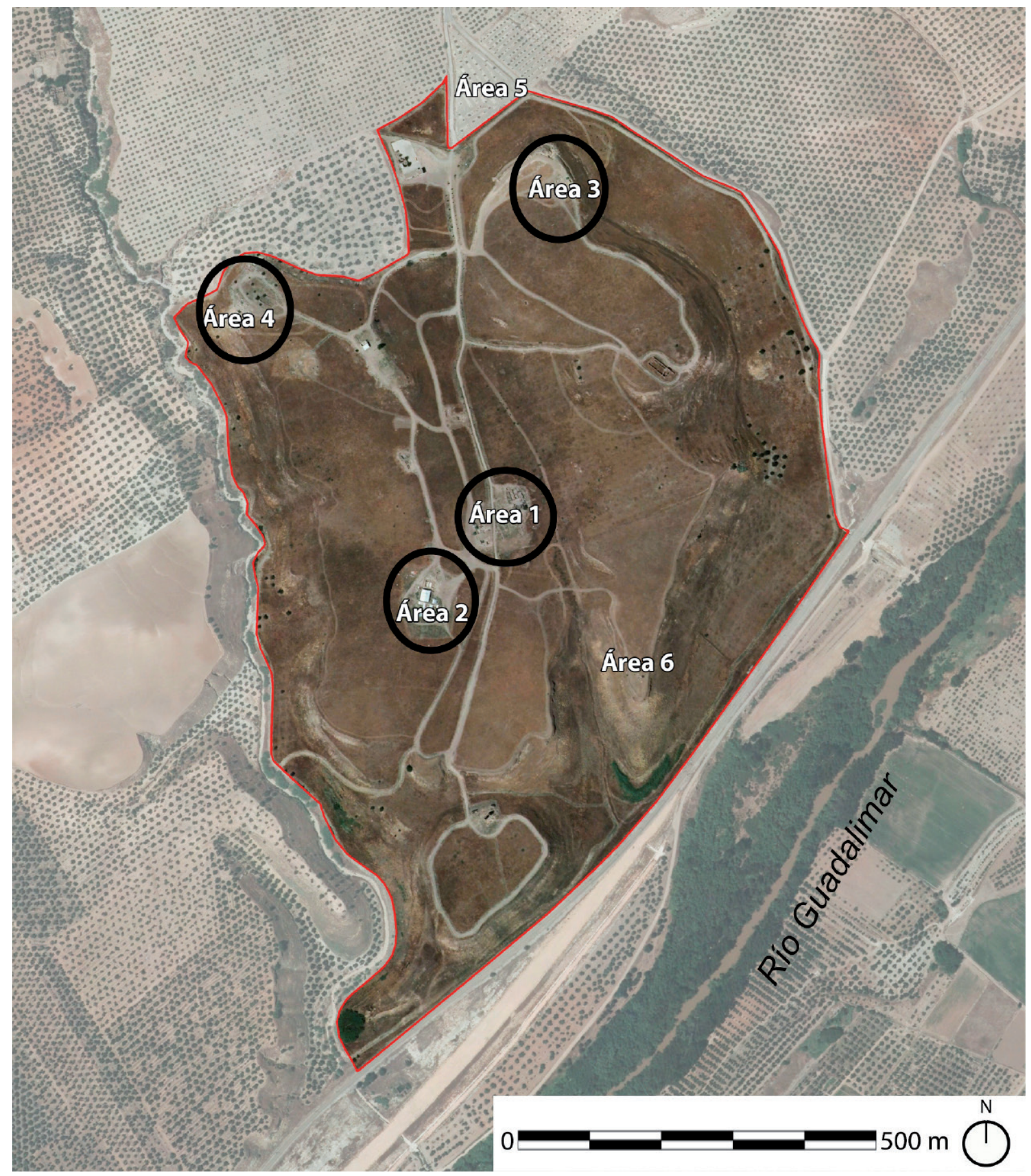

Figura 2. Delimitación de Cástulo y de las áreas analizadas.

a rodales. La vegetación potencial es un encinar, pobre en especies y de talla media, que en sus zonas más cálidas se enriquece con lentiscos y acebuches, mientras que las umbrías aparecen quejigos (Rivas Martínez 1987, Valle, 2004) (fig. 1).
Al norte del asentamiento y de la ciudad de Linares, en Sierra Morena los suelos son silíceos, lo que provoca un cambio de las series de vegetación. En esta zona, en el piso mesomediterráneo se desarrollan encinares y alcornocales que se imbrican entre sí, con asociaciones 
vegetales de difícil interpretación. En estas formaciones son comunes los madroños. Si ascendemos un poco podemos encontrar quejigos y robles melojos (fig. 1).

\subsection{Materiales y método de estudio}

El material de estudio procede tanto de la recogida manual de carbones, como de la recogida sistemática de muestras de sedimento para su procesado por flotación. El muestreo sistemático durante las campañas de 2011 a 2014 consistió en la recogida de 401 de sedimento por UE. A partir de la campaña de 2015 se realizó una recogida selectiva de aquellas UEs potencialmente ricas en restos arqueobotánicos, aunque el volumen de sedimentos se aumentó, recogiendo hasta 1001.

Esta combinación de métodos de recogida ha permitido obtener una importante cantidad de carbones a nivel global. Se han estudiado un total de 3234 fragmentos, provenientes de 144 muestras estudiadas que pertenecen a 84 Unidades Estratigráficas (tab. 1) y de las áreas del yacimiento excavadas en las campañas de 2011 a 2015 (Áreas 1-4) (fig.2).

Para la visualización de los carbones se ha utilizado el microscopio de luz reflejada (Olympus BX50) del Laboratorio de Paleoambiente del Instituto Universitario de Investigación en Arqueología Ibérica de la Universidad de Jaén (IUIAI).

La unidad de medida ha sido el fragmento de carbón, a partir del cual se realizan los gráficos y la interpretación antracológica. Si bien a nivel global la cantidad de carbones recuperados es importante, ha sido escasa a nivel de las distintas UEs, lo que ha impedido realizar una valoración individual de ellas y un análisis microespacial de los resultados. Esta escasez de carbones por UE, junto a su pequeño tamaño, ha hecho que se estudien casi la totalidad de los existentes y se haya realizado un esfuerzo en la determinación.
El estudio espacial de los resultados se ha realizado a nivel semimicro, comparando los resultados obtenidos en las distintas áreas por periodos culturales (tab. 2). Los distintos periodos culturales se han definido atendiendo a la cronología que proporcionan los materiales encontrados en ellas, ya que el análisis estratigráfico de la excavación y la definición de las distintas fases constructivas aún no se ha terminado de realizar (Pérez 2014, Castro 2015, Ceprián et al. 2016, Soto et al. 2018).

La identificación antracológica de los taxones se ha realizado a partir de la comparación de la anatomía del xilema secundario con varios atlas de anatomía de la madera (Schweingruber 1990, Vernet 2001, Schweingruber, Börner y Schulze 2011 y 2013) y con la colección de maderas actuales carbonizadas del IUIAI.

La identificación anatómica del carbón suele llegar al nivel de especie, aunque en muchos casos se queda en el género (Cistus, Fraxinus, Juniperus, Phillyrea, Prunus y Vitis) (tab. 2). Sin embargo, algunos taxones pueden estar representando a dos especies, como es el caso de Quercus ilex-coccifera que integra a la encina (Quercus ilex) y a la coscoja (Quercus coccifera); o dos géneros como en Salix-Populus, que integra a todas las especies de sauces y álamos. En el caso de la Olea europea, a través de la antracología no se puede diferenciar entre la variedad silvestre (acebuche) y la cultivada (olivo).

La interpretación antracológica se ha realizado a partir del espectro florístico o lista de taxones determinados (tab. 2), mientras que los gráficos y el diagrama se expresan en frecuencias relativas. El estudio paleoecológico está basado en la interpretación del diagrama antracológico (fig. 3), el cual está realizado con los carbones hallados dispersos en los estratos arqueológicos (3234 fragmentos analizados), habiéndose excluido los recuperados en los hogares, hoyos de poste, etc. En la tabla 2 se detallan los taxones

Tabla 1. Relación del número de muestras, fragmentos de carbón analizados y UEs estudiadas en el análisis antracológico de Cástulo (Campañas 2011-2015).

\begin{tabular}{|l|c|c|c|c|c|c|c|}
\cline { 2 - 8 } \multicolumn{1}{c|}{} & $\begin{array}{c}\text { Bronce } \\
\text { Final }\end{array}$ & Ibérico & Romano & $\begin{array}{c}\text { Tardoanti- } \\
\text { güedad }\end{array}$ & $\begin{array}{c}\text { Alta Edad } \\
\text { Media }\end{array}$ & Islámico & Total \\
\hline $\mathrm{N}^{\mathrm{o}}$ muestras estudiadas & 1 & 21 & 63 & 54 & 4 & 1 & 144 \\
\hline $\mathrm{N}^{\mathrm{o}} \mathrm{UE}$ estudiadas & 1 & 13 & 41 & 25 & 3 & 1 & 84 \\
\hline $\mathrm{N}^{\mathrm{o}}$ frag. carbones estudiados & 11 & 595 & 1586 & 934 & 100 & 8 & 3234 \\
\hline
\end{tabular}


Tabla 2: Frecuencias absolutas y relativas de los taxones identificados en el antracoanálisis de Cástulo (campañas 2011-2015).

\begin{tabular}{|c|c|c|c|c|c|c|c|c|c|}
\hline \multirow{3}{*}{$\begin{array}{l}\text { Período Cultural } \\
\text { CRONOLOGÍA }\end{array}$} & \multirow{3}{*}{$\begin{array}{l}\text { Bronce } \\
\text { Final }\end{array}$} & \multicolumn{8}{|c|}{ Ibérico } \\
\hline & & \multicolumn{2}{|c|}{ Antiguo } & \multicolumn{2}{|c|}{ Antiguo/ Pleno } & \multicolumn{2}{|c|}{ Pleno } & \multicolumn{2}{|c|}{ Tardío } \\
\hline & & \multicolumn{2}{|c|}{ S.VII-VI a.C. } & \multicolumn{2}{|c|}{ S. VI-IV a.C. } & \multicolumn{2}{|c|}{ S. IV-III a. C. } & \multicolumn{2}{|c|}{ S. III-II a.C. } \\
\hline Taxones & $\mathrm{N}^{\mathrm{o}}$ & $\mathrm{N}^{\mathrm{o}}$ & $\%$ & $\mathrm{~N}^{\mathrm{o}}$ & $\%$ & $\mathrm{~N}^{\mathrm{o}}$ & $\%$ & $\mathrm{~N}^{\mathrm{o}}$ & $\%$ \\
\hline Arbutus unedo & & & 28.51 & 17 & 10.96 & 18 & 20.22 & 13 & 11.2 \\
\hline \multicolumn{10}{|l|}{ Cistus sp. } \\
\hline Fraxinus sp. & 1 & 4 & 1.7 & 10 & 6.45 & & & & \\
\hline \multicolumn{10}{|l|}{ Juniperus sp. } \\
\hline Olea europaea & & 9 & 3.82 & 5 & 3.22 & 5 & 5.61 & & \\
\hline Phillyrea sp. & & 3 & 1.29 & & & & & & \\
\hline Pinus halepensis & & 1 & 0.43 & 3 & 1.95 & & & & \\
\hline Pistacia lentiscus & & 4 & 1.71 & & & 1 & 1.13 & & \\
\hline Prunus domestica & & 1 & 0.43 & 5 & 3.22 & & & & \\
\hline \multicolumn{10}{|l|}{ Prunus dulcis } \\
\hline Prunus sp. & & & & 1 & 0.65 & & & & \\
\hline $\begin{array}{l}\text { Quercus ilex/ } \\
\text { coccifera }\end{array}$ & 10 & 139 & 59.14 & 108 & 69.67 & 63 & 70.8 & 103 & 88.8 \\
\hline Salix/Populus & & & & 2 & 1.3 & & & & \\
\hline \multicolumn{10}{|l|}{ Vitis vinifera } \\
\hline Indeterminables & & 7 & 2.97 & 4 & 2.58 & 2 & 2.24 & & \\
\hline TOTAL CARBONES & 11 & 235 & 100 & 155 & 100 & 89 & 100 & 116 & 100 \\
\hline $\mathrm{N}^{\mathrm{o}}$ TAXONES & 2 & 8 & & 8 & & 4 & & 2 & \\
\hline
\end{tabular}

identificados y las frecuencias relativas y absolutas de ellos en cada uno de los 13 periodos cronológicos determinados, que se agrupan en 6 periodos culturales, aunque tanto el primero (Bronce Final) como el último (Islámico), al tener muy poco carbón, no se han representado en el diagrama. Asimismo, se indican las frecuencias de los fragmentos que no hemos podido identificar (Indeterminadas) y de los carbones que por su mal estado (pertenecientes a nudos, vitrificados, con concreciones calcáreas,...) son imposibles de conocer (Indeterminables). También, en la fila final de la tabla se indican el número total de carbones analizados y el número de taxones identificados, que nos permite una evaluación rápida de la riqueza florística de cada una de las fases analizadas.
Las frecuencias relativas que aparecen en este cuadro son las utilizadas para la confección del diagrama antracológico (fig. 3).

La ordenación de los taxones en el diagrama se ha realizado poniendo en primer lugar la especie de Gimnospermas determinada, el Pino carrasco (Pinus halepensis), seguido de los taxones de la vegetación natural, ordenados alfabéticamente, de donde se han excluidos las especies de ribera, que se han puesto a continuación seguidos por los taxones de las especies cultivadas. En este diagrama la Olea europea en un primer momento se ha considerado como especie natural (acebuche), mientras que en un segundo como especie cultivada (olivo). Este hecho se explicará convenientemente en los apartados siguientes. Los valores con menos del 1\% 
Tabla 2: Frecuencias absolutas y relativas de los taxones identificados en el antracoanálisis de Cástulo (campañas 2011-2015). Continuación

\begin{tabular}{|c|c|c|c|c|c|c|c|c|c|c|c|c|c|c|c|}
\hline \multirow{4}{*}{$\begin{array}{l}\text { Período Cultural } \\
\text { CRONOLOGÍA } \\
\text { Taxones }\end{array}$} & \multicolumn{7}{|c|}{ Romano } & \multicolumn{4}{|c|}{ Tardoantiguedad } & \multicolumn{3}{|c|}{ Alta E. Media } & \multirow{4}{*}{$\begin{array}{c}\text { Islámico } \\
\mathrm{N}^{\mathrm{o}}\end{array}$} \\
\hline & \multicolumn{4}{|c|}{ Republicano } & \multirow{2}{*}{\multicolumn{2}{|c|}{$\begin{array}{l}\text { Alto Imp. } \\
\text { S. I-III d.C. }\end{array}$}} & \multirow{2}{*}{\multicolumn{2}{|c|}{ S. IV-V d.C. }} & \multirow{2}{*}{\multicolumn{2}{|c|}{ S. V-VIII d.C. }} & \multirow{2}{*}{\multicolumn{2}{|c|}{ S. VIII-IX d.C. }} & \multirow[b]{3}{*}{$\mathrm{N}^{\mathrm{o}}$} & \multirow[b]{3}{*}{$\%$} & \\
\hline & S. II- & I a.C. & S. I a. & -I d.C. & & & & & & & & & & & \\
\hline & $\mathrm{N}^{\mathrm{o}}$ & $\%$ & $\mathrm{~N}^{\mathrm{o}}$ & $\%$ & $\mathrm{~N}^{\mathrm{o}}$ & $\%$ & $\mathrm{~N}^{\mathrm{o}}$ & $\%$ & $\mathrm{~N}^{\mathrm{o}}$ & $\%$ & $\mathrm{~N}^{\mathrm{o}}$ & $\%$ & & & \\
\hline Arbutus unedo & 11 & 3.13 & & & & & 1 & 0.13 & & & & & & & \\
\hline Cistus sp. & & & & & & & & & 5 & 0.7 & & & & & \\
\hline Fraxinus sp. & 2 & 0.58 & & & 6 & 2.47 & 30 & 3.65 & 10 & 1.37 & 4 & 1.94 & 2 & 2 & \\
\hline Juniperus sp. & & & & & & & & & 4 & 0.56 & & & & & \\
\hline Olea europaea & 25 & 7.12 & 36 & 20.9 & 72 & 29.75 & 192 & 23.38 & 195 & 26.85 & 65 & 31.25 & 32 & 32 & 3 \\
\hline Phillyrea sp. & 6 & 1.7 & 5 & 2.91 & 1 & 0.42 & 1 & 0.13 & 11 & 1.51 & & & & & \\
\hline Pinus halepensis & 25 & 7.12 & 48 & 27.9 & 36 & 14.85 & 156 & 19 & 128 & 17.63 & 35 & 16.82 & 5 & 5 & 2 \\
\hline Pistacia lentiscus & 27 & 7.69 & 8 & 4.66 & 1 & 0.42 & 31 & 3.78 & 18 & 2.47 & 7 & 3.36 & 2 & 2 & \\
\hline Prunus domestica & 15 & 4.27 & 6 & 3.5 & 4 & 1.65 & 19 & 2.31 & 17 & 2.34 & 5 & 2.4 & & & \\
\hline Prunus dulcis & 3 & 0.86 & & & 2 & 0.84 & & & 2 & 0.28 & & & 1 & 1 & \\
\hline Prunus sp. & 2 & 0.58 & & & 1 & 0.42 & 3 & 0.36 & 5 & 0.7 & & & & & \\
\hline $\begin{array}{l}\text { Quercus ilex/ } \\
\text { coccifera }\end{array}$ & 225 & 64.1 & 68 & 39.53 & 117 & 48.34 & 365 & 44.45 & 308 & 42.42 & 90 & 43.26 & 57 & 57 & 3 \\
\hline Salix/Populus & & & & & & & 2 & 0.26 & 3 & 0.42 & & & & & \\
\hline Vitis vinifera & 1 & 0.29 & & & & & & & 1 & 0.14 & & & & & \\
\hline Indeterminables & 9 & 2.56 & 1 & 0.6 & 2 & 0.84 & 21 & 2.55 & 19 & 2.61 & 2 & 0.97 & 1 & 1 & \\
\hline TOTAL CARBONES & 351 & 100 & 172 & 100 & 242 & 100 & 821 & 100 & 726 & 100 & 208 & 100 & 100 & 100 & 8 \\
\hline $\mathrm{N}^{\mathrm{o}}$ TAXONES & 11 & & 6 & & 9 & & 10 & & 13 & & 6 & & 6 & & 3 \\
\hline
\end{tabular}

están representados por cuadros, mientras que la última columna a la derecha recoge los taxones que aparecen ocasionalmente.

\section{RESULTADOS}

\subsection{A nivel cuantitativo}

El hecho de contar con un desigual número de carbones analizados por fase, dos de ellas con un número igual o inferior a 100 fragmentos: Ibérico Pleno con 89 y Alta Edad Media con 100, nos ha llevado a poner en relación el número de carbones analizados (fig. 4.a) con el número de taxones identificados por fase (fig. 4.b), para determinar si el segundo estaba en función del primero. La comparación de estos dos gráficos nos demuestra que el número de taxones no está en función del número de carbones analizados.

Así, la fase del siglo IV-V d.C., con 821 carbones analizados, no es la fase en que más taxones se han determinado, al igual que la mencionada fase del Ibérico Pleno, con 89 fragmentos, no es la que menos taxones tiene. Por tanto, la presencia o ausencia de los taxones es debida la presencia o no en el entorno, junto con la gestión que de las determinadas especies se realizó en cada momento.

En la figura 4.b observamos que en los niveles del Ibérico Antiguo y Antiguo/Pleno hay 8 taxones determinados en cada periodo, bajando hasta tres y dos taxones 


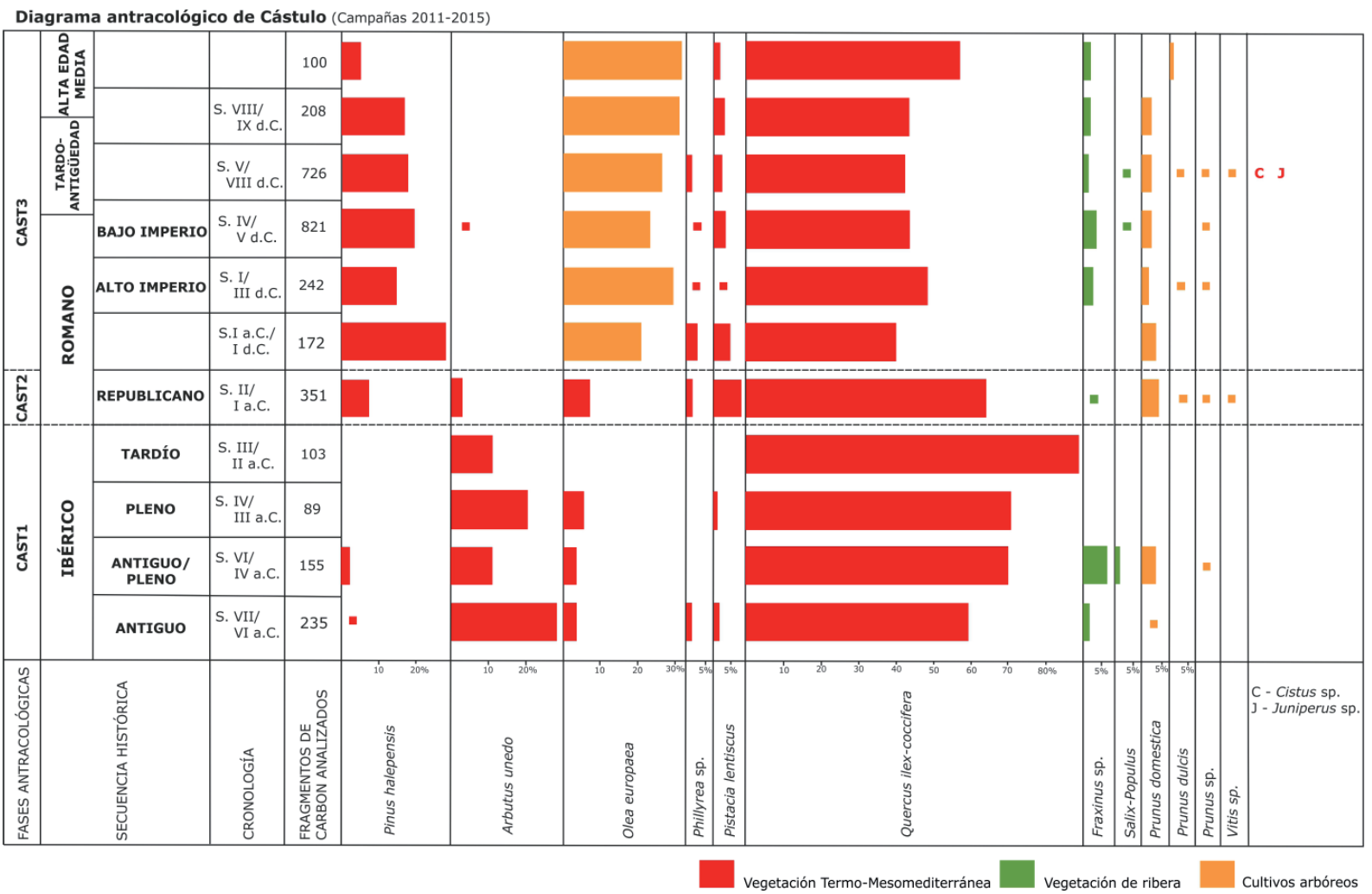

Figura 3. Diagrama antracológico de Cástulo.

en los periodos del Ibérico Pleno y Tardío, en este caso en relación con la menor cantidad de carbón analizado. La cifra total de taxones determinados para este período es de 10 , cantidad escasa si la comparamos con los 28 determinados en el conjunto del antracoanálisis de Puente Tablas (Rodríguez-Ariza 2017) (fig. 1).

En el periodo romano republicano, aunque la cifra global solo aumenta en 1 taxón, sí se observa un aumento si lo comparamos con la media de las fases anteriores. En el tramo siguiente del gráfico, que comprende los 6 periodos cronológicos entre el cambio de era y la Alta Edad Media, el número de taxones aumenta globalmente hasta 14, aunque la media se mantiene en 8.33, indicando que este aumento solo se da por la aparición ocasional de algunos de los taxones.

Este primer análisis cuantitativo de los taxones determinados nos informa acerca de cómo la riqueza florística ha aumentado ligeramente a lo largo de la secuencia, en este caso por la aparición de varios árboles cultivados, como el ciruelo, el almendro y la vid, este último no documentado en época ibérica en este asentamiento, aunque sí en otros cercanos como Puente Tablas (Rodríguez-Ariza 2017). Es posible que la naturaleza urbana de la mayoría de los depósitos excavados, principalmente en las áreas 1 y 2, como anteriormente se ha señalado, de donde provienen las muestras, esté condicionando la no aparición de un mayor número de taxones. Esta cuestión habrá de ser resuelta conforme se avance en el estudio antracológico del conjunto de Cástulo

\subsection{A nivel cualitativo: La evolución de la vegetación y su gestión}

Las variaciones a nivel cualitativo de la riqueza florística a lo largo del tiempo, junto con las variaciones de los porcentajes de los distintos taxones en el diagrama antracológico de Cástulo, son las que nos han hecho determinar tres fases antracológicas. Estas fases se han señalado en la primera columna del diagrama con la abreviatura del yacimiento (CAST de Cástulo) seguidas de un número (fig. 3).

La primera fase antracológica (CAST1) se corresponde con el periodo ibérico comprendido entre el siglo VII a.C. y el siglo II a.C. Esta fase está caracterizada por la gran frecuencia de aparición de la encina 
Figura 4: Comparación entre: a) Número de fragmentos de carbón estudiados por periodo cronológico. b) Número de taxones identificados por periodo y fases antracológicas.

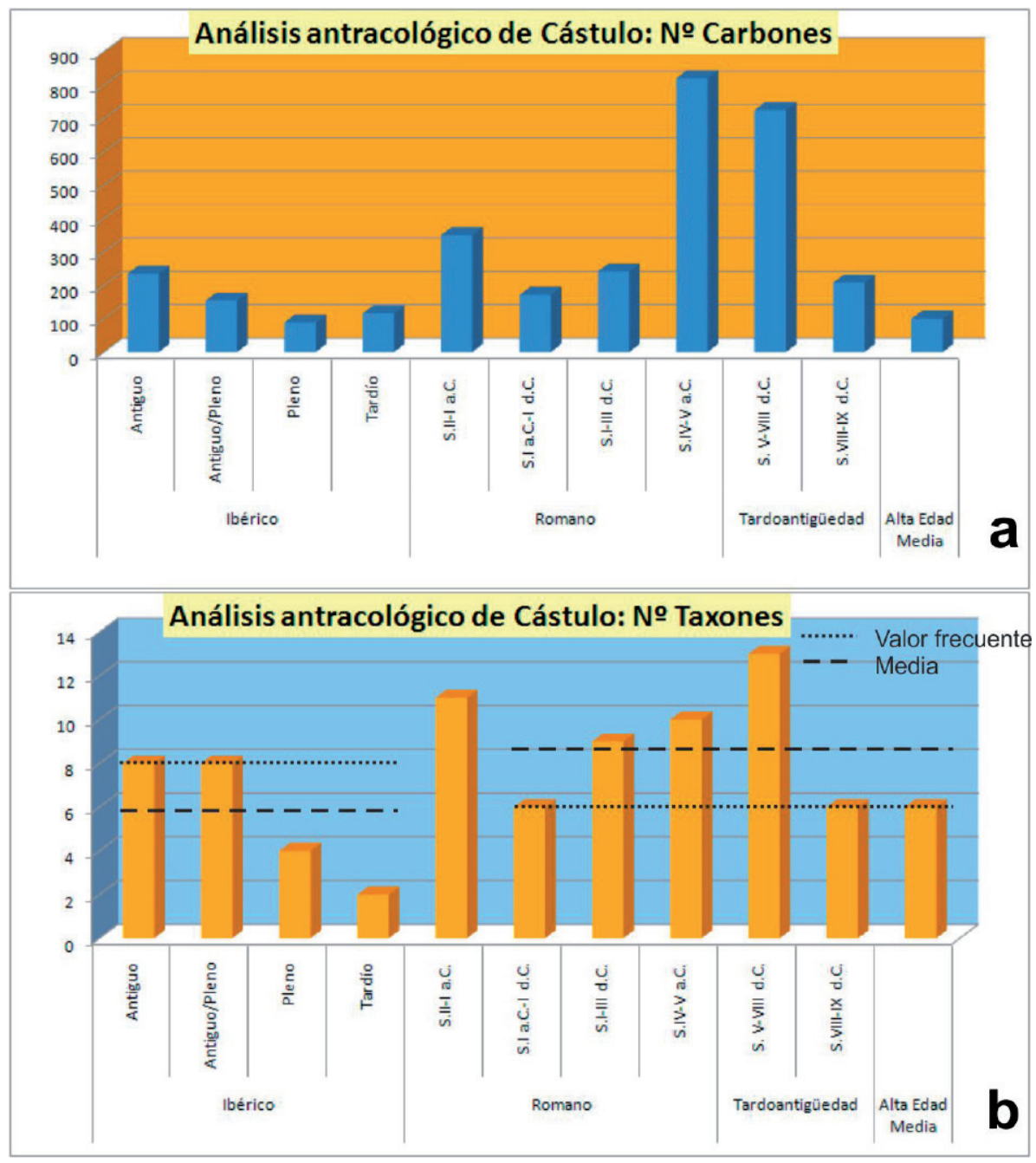

y/o coscoja (Quercus ilex-coccifera) con porcentajes que oscilan entre el 60-88\%. En segundo lugar, aparece el madroño (Arbutus unedo) con porcentajes entre el 28 y el $11 \%$. Junto a estas dos especies, que nos hablan de un ambiente de encinar más o menos bien formado, aparecen acebuches (Olea europea), labiérnagos (Phillyrea sp.) y lentiscos (Pistacia lentiscus) que indican un ambiente termófilo, donde las heladas son escasas y se pueden desarrollar estas especies del sotobosque. La presencia de otras especies climácicas es escasa, con la aparición ocasional del pino carrasco ( $P i$ nus halepensis).

La ripisilva aparece representada por los fresnos (Fraxinus sp.) y los sauces y/o álamos (Salix-Populus), aunque solo en las dos fases primeras, faltando en las dos últimas. Igualmente, los cultivos arbóreos solo aparecen en las dos primeras fases y con el ciruelo (Prunus domestica) como única especie presente, aunque con algún fragmento del género de las prunoideas.

En esta fase, por tanto, hay que destacar la presencia de un ambiente de encinar, aunque se han determinado pocos taxones, 10 en total, lo que contrasta con los datos del análisis antracológico de Puente Tablas (Rodríguez-Ariza 2017), donde se han determinado hasta 23 taxones. Esta escasez de taxones puede responder tanto a condiciones medioambientales de presencia/ausencia de especies en el entorno o de gestión forestal, como a problemas tafonómicos y de la naturaleza de estructuras y niveles arqueológicos analizados. En este sentido las muestras provienen principalmente de las áreas 2, donde los niveles ibéricos no están estructuralmente bien definidos, al encontrarse por debajo del edificio D romano, y de la 4, por debajo del Santuario púnico de Torre Alba. 
La segunda fase antracológica (CAST2) se corresponde con la fase del siglo II-I a.C. que, en las distintas zonas del yacimiento, unas veces venía indicado como romano republicano y en otras como Ibérico Final.

A nivel antracológico es un momento donde prácticamente contamos con los mismos taxones de la fase anterior, aunque desaparecen los sauces/álamos y aparece el almendro. Lo remarcable es el cambio en los porcentajes de varias de las especies, lo que indica el periodo de transición de este momento. Así, el madroño desciende hasta el 3\%, mientras que la Olea europea y el pino carrasco aumentan hasta el 7\% cada uno. Estos cambios indican que la roturación del encinar se ha extendido en el entorno de Cástulo haciendo desaparecer, con probabilidad, las formaciones de matorrales más umbrófilos de madroño. Estas formaciones que ocuparían tierras húmedas y fértiles son eliminadas para la introducción de nuevos cultivos, como son los almendros y los primeros ejemplares de olivo. Este hecho provoca que especies como el pino carrasco se desarrollen en los nuevos espacios abiertos y soleados. El encinar quedaría relegado a las zonas más secas y con mayores pendientes, donde siguen desarrollándose el lentisco y los labiérnagos.

Esta tendencia se acentúa en la tercera fase antracológica (CAST3) que se inicia a partir del siglo I d.C. y que llega hasta la Alta Edad Media. Esta fase, en la que podemos incluir hasta 6 periodos cronológicoculturales que comprenden casi el primer milenio de nuestra era, presenta una gran homogeneidad en las frecuencias de los taxones presentes, lo cual nos indicaría cómo el paisaje vegetal y su gestión a lo largo de los siglos casi permanece inalterable.

En esta fase destaca el descenso relativo de la encina/coscoja hasta el 40-50\% y la desaparición del madroño, con solo una aparición ocasional en el siglo IV-V d.C. Asimismo, destaca el fuerte aumento de la Olea europaea en el siglo I d.C. con el 20\%, porcentaje que se mantiene o aumenta hasta el $32 \%$. Por lo que consideramos que estamos ante la variedad cultivada, es decir, el olivo. Este mismo fenómeno de aumento del porcentaje de la Olea europea en el siglo I d.C. lo hemos constatado en otros yacimientos de Andalucía, incluso en zonas donde el acebuche no se da de forma natural (Rodríguez-Ariza y Montes 2005), lo cual indica que la introducción a gran escala del olivo se produce en torno al cambio de era.

Junto al olivo, la arboricultura se desarrolla con otras especies de árboles cultivados como son el ciruelo, ya presente en época ibérica, el almendro y la vid, aunque esta última aparece ocasionalmente en dos fases.
El pino carrasco, cuya aparición se produjo en la fase anterior, se consolida a lo largo de la secuencia con porcentajes ente el 14 y el 19\%, indicando cómo los espacios abiertos están presentes en el entorno de Cástulo, al igual que existe una ripisilva en el río Guadalimar representada por los fresnos y la presencia ocasional de sauces y álamos.

\subsection{Estudio espacial de los resultados}

Aunque el número global de carbones analizados es importante, no es suficiente, como anteriormente se ha comentado, para poder realizar una valoración individual de las distintas UEs, ni hacer un análisis estructural de los resultados. Sin embargo, si se puede realizar un análisis semimicro, comparando los resultados obtenidos en las distintas áreas por periodos culturales (tab. 2) o por las fases antracológicas definidas (fig. 3). La comparación de resultados por zonas de excavación tiene el objetivo de ver si los resultados son similares o reflejan una misma composición de la vegetación, o por el contrario indican un uso diferencial de las distintas especies.

La escasez de carbón recuperado en los distintos periodos culturales impide hacer una comparación de resultados entre todas las zonas y todos los periodos. En primer lugar, porque en las distintas áreas no se han excavados los mismos periodos cronológicos y, en segundo, porque en muchos el número de carbón recuperado ha sido escaso. Por tanto, se han seleccionado los periodos y zonas en las que existían suficientes fragmentos de carbón analizados que nos permiten su comparación.

Del periodo del Ibérico Antiguo/Pleno (siglos VIIV a.C.) se han estudiado 87 fragmentos de carbón del Área 2 y 68 del Área 3. La determinación antracológica ha proporcionado una lista floral de 7 y 6 taxones respectivamente. A nivel porcentual se distribuyen de manera bastante similar en las dos áreas, con la encina/coscoja como principal taxón determinado, y el madroño y los fresnos como segundo y terceros, aunque a bastante distancia del primero. El resto de taxones aparecen en pequeña cantidad y en un área u otra (fig. 5).

Del periodo altoimperial romano (siglos I-III d.C.) se han estudiado 94 carbones del Área 1 y 148 del Área 2 , con 5 y 7 taxones determinados respectivamente en cada área, aunque solo 3 son comunes a las dos áreas. El taxón mayor es la encina/coscoja, el segundo, el olivo y el tercero el pino carrasco. Es de resaltar que 
Figura 5. Comparación de las frecuencias relativas de los taxones determinados en las Áreas 2 y 3 durante el Ibérico Antiguo/Pleno.

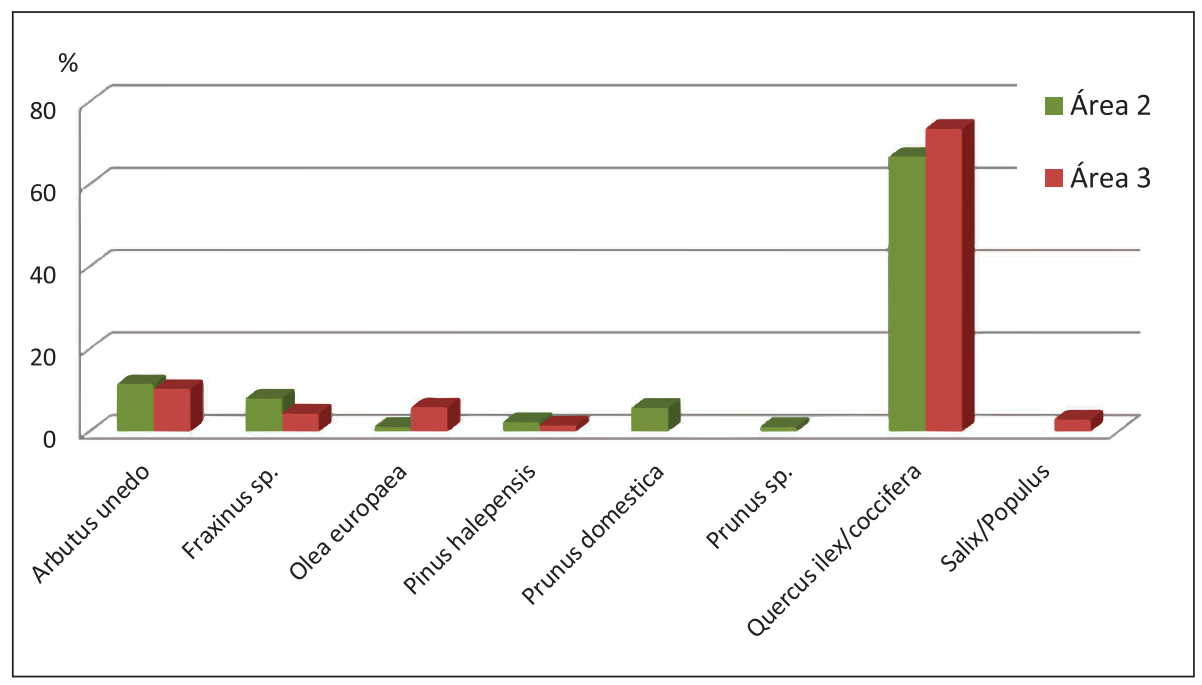

entre la encina/coscoja y el pino carrasco existe una relación inversa entre las dos zonas, con una disparidad de porcentajes, sin que podamos, por el momento, dar una explicación a este hecho. Sin embargo, estos tres taxones a nivel de presencia son los tres principales en cada área y los que representan entre el 85 y el 91\% de frecuencia. El resto de taxones aparecen en una u otra área con porcentajes por debajo del 5\% (fig. 6).

Del periodo tardoantiguo (siglos V-VIII d.C.) se han analizado 190 fragmentos de carbón en el Área 2 y 92 en el Área 4. De los 12 taxones determinados, 5 son comunes a las dos áreas con similares porcentajes, mientras que de los 7 restantes, 5 aparecen solo en el Área 2 y 2 en el Área 4 (fig. 7). Hay que remarcar que los 3 taxones mayores, encina/coscoja, pino carrasco y olivo, presentan una gran homogeneidad de los porcentajes, representando en los dos casos el $89 \%$ de frecuencia.

En los tres casos en que se han podido comparar las frecuencias los taxones mayores son coincidentes en importancia y en representación, indicando que se han utilizado las mismas especies con un uso parecido y a su existencia en el entorno del asentamiento. Por tanto, los resultados a nivel global del yacimiento pueden ser considerados como válidos y como el reflejo de la existencia de formaciones vegetales naturales y cultivadas, que denotan la gestión forestal y de cultivos arbóreos que los habitantes de Cástulo hicieron a lo largo de la historia.
Figura 6. Comparación de las frecuencias relativas de los taxones determinados en las Áreas 1 y 2 durante el Alto Imperio.

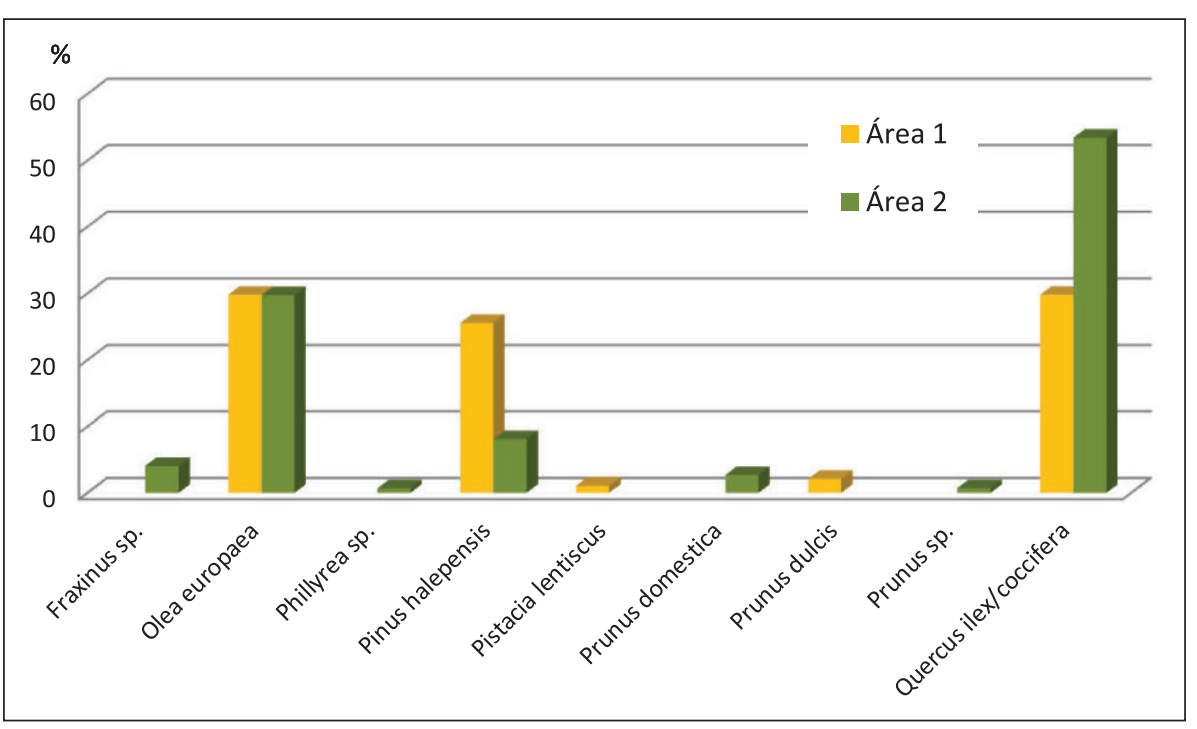




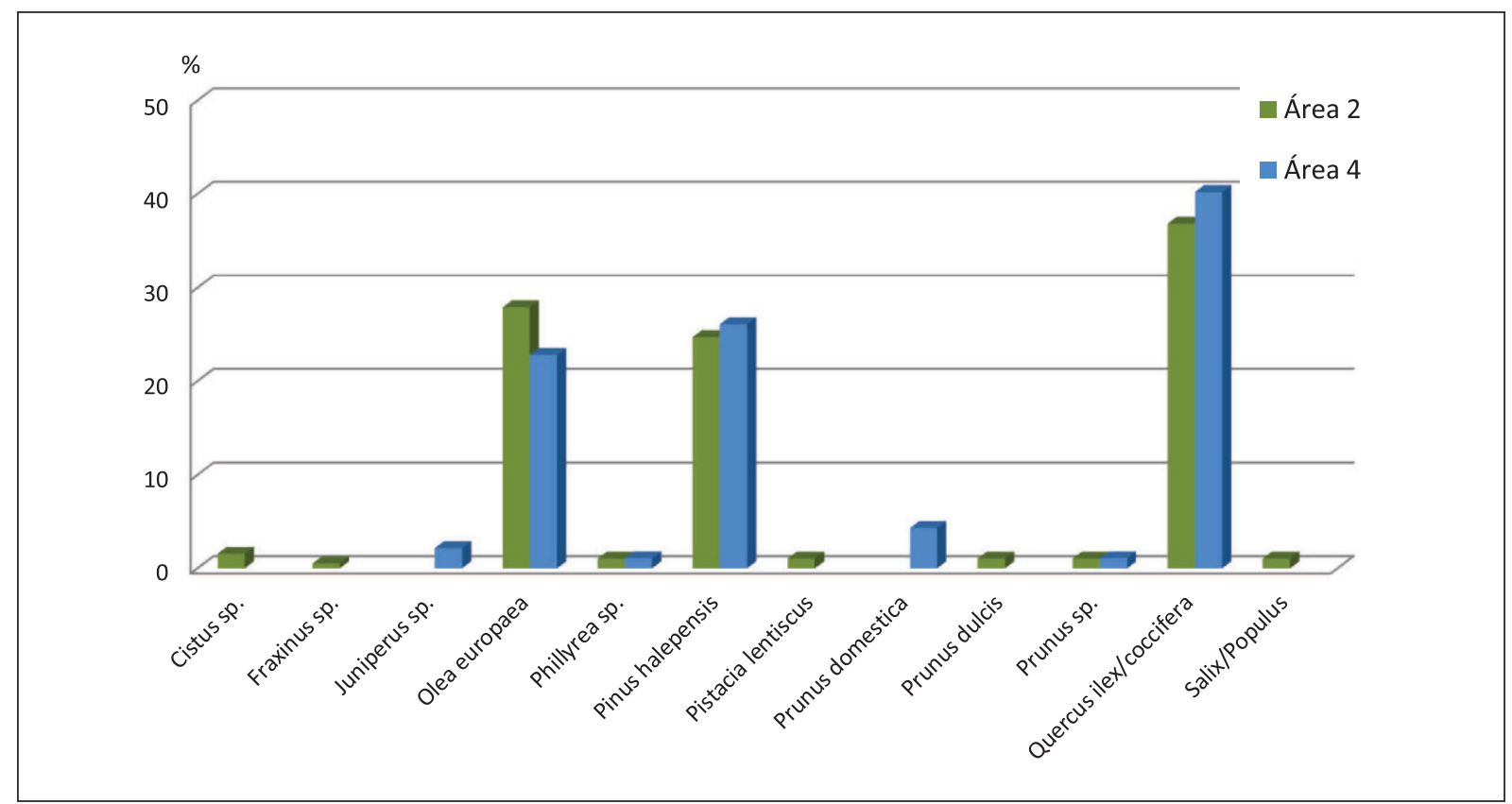

Figura 7. Comparación de las frecuencias relativas de los taxones determinados en las Áreas 2 y 4 durante los niveles tardoantiguos.

\section{VALORACIÓN Y DISCUSIÓN}

Las tres fases antracológicas definidas reflejan una imagen diferencial del entorno vegetal de Cástulo, siendo la Fase antracológica 2 (CAST2) un periodo de transición entre la Fase 1 y la 3. Este cambio se produce en un doble sentido: por un lado, a nivel cualitativo cambia la formación vegetal del entorno y, por otro, a nivel cuantitativo se produce la disminución o el aumento de los grupos de vegetación o especies. Pero, definamos primero la vegetación de época ibérica para después valorar el cambio que se produce a partir del siglo I d.C.

Como ya se ha señalado antes, en época ibérica se han determinado solo 10 taxones. Este hecho parece reflejar una formación de encinar, pobre en especies, más característico de los encinares silicícolas, actualmente al norte de Linares (fig. 1) que de los basófilos donde se enmarca Cástulo. Por tanto, el mayor grado de humedad relativa que denota la existencia de madroño en los alrededores de Cástulo explicaría también que esta especie pudiera vivir sobre sustratos básicos al disolver el carbonato cálcico y dejar como residuo los silicatos (Varo et al. 1977), lo cual da entrada a la instalación en ellos de plantas silicícolas, como es el caso de las comunidades de madroño (Torres et al. 2002). Esta presencia del madroño se ha constatado en la zona desde el Paleolítico hasta época ibérica, en yacimientos como la Cueva de los Murciélagos de Zuheros, Polideportivo de Martos, Marroquíes Bajos (Rodríguez-Ariza 2011) o Puente Tablas (Rodríguez-Ariza 2017).

En Puente Tablas se determinaron 23 taxones, destacando principalmente el conjunto de árboles frutales con nogales, ciruelos, almendros y vides, que representan cerca del 30\% de los fragmentos determinados en el Palacio. Esto nos indica un gran desarrollo agrícola de los iberos de Puente Tablas, ya que los cultivos de ciclo largo como los árboles frutales necesitan de conocimientos agrícolas importantes, así como de un alto desarrollo social que garantice la propiedad de estos cultivos, que necesitan varios años para dar fruto. Estas especies irían, por un lado, destinadas al consumo, pero también al comercio, caso especialmente de la vid para la obtención del vino. Este hecho parece no darse en la Cástulo ibérica, donde solo hemos determinado ciruelo, cuestión que se podría explicar debido a la naturaleza del registro hasta ahora analizado de época ibérica, no muy abundante, y por las características de las estructuras y niveles analizados, y como se ha señalado anteriormente, no claramente definidos. Hasta que no avancen los estudios arqueobotánicos, tanto carpológicos como antracológicos, no parece oportuno aventurar otra explicación a este hecho.

El cambio cualitativo de las formaciones vegetales entre el periodo ibérico y el mundo romano es muy 


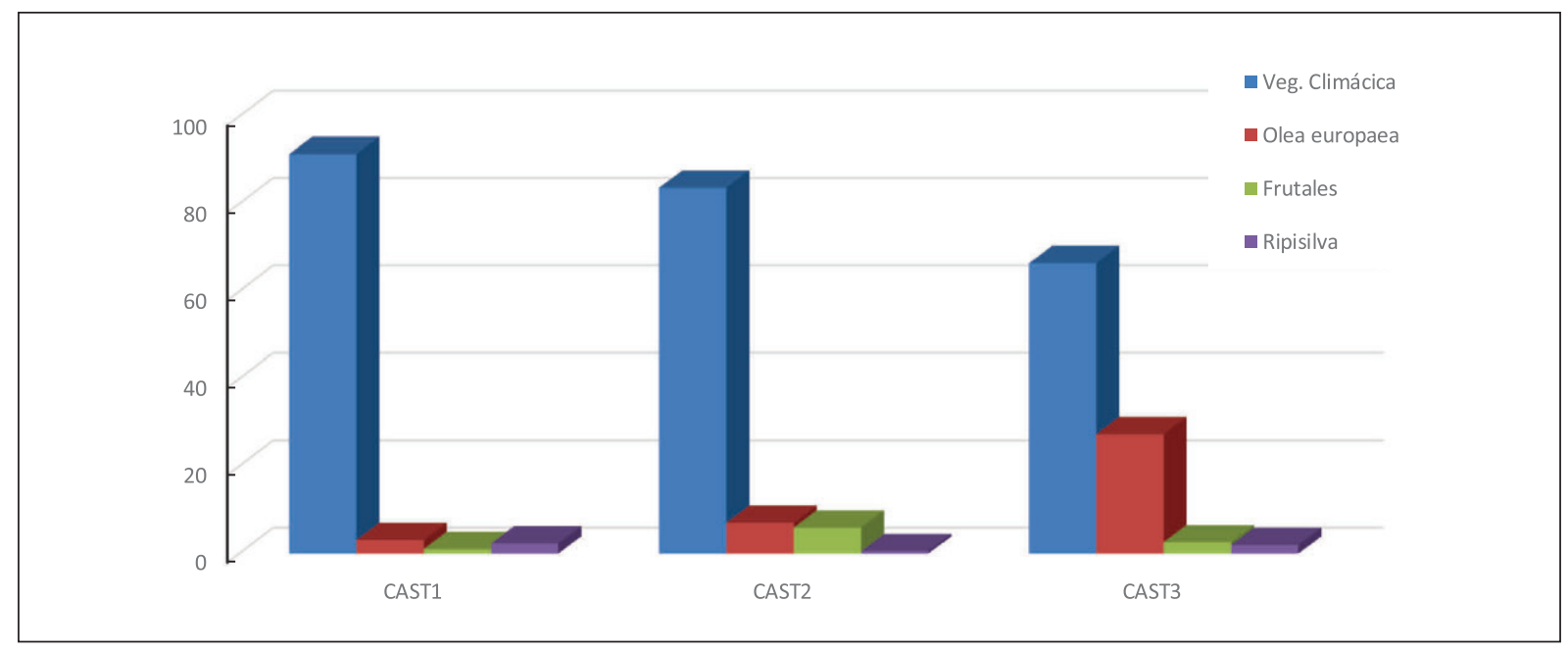

Figura 8. Comparación de las frecuencias relativas de los grupos de vegetación entre las tres fases antracológicas.

importante, de un entorno donde predomina una vegetación de encinar se pasa a un espacio donde los cultivos arbóreos, principalmente el olivar, dominan el territorio. Esta transformación se produce como consecuencia de un distinto modelo económico y de ordenación del territorio, con la introducción del cultivo del olivo alrededor del cambio de era. Proceso que también hemos documentado en otras áreas del Mediterráneo, como Utica en Túnez (Rodríguez-Ariza et al. 2020), y que responde a la implantación de una agricultura "capitalista" por parte de los grandes latifundistas romanos, para abastecer a la metrópolis de productos básicos como el aceite, lo que les proporciona importantes beneficios.

La transformación del entorno de Cástulo se realiza roturando el "bosque" y ampliando las zonas agrícolas, quedando la vegetación natural reducida a rodales y a las zonas montañosas cercanas. Aunque el descenso de la representación de la vegetación climácica es apreciable, en torno a un $25 \%$, en correspondencia con el aumento de la Olea también cifrado en el $24 \%$, esta sigue siendo la más utilizada por los habitantes de Cástulo para el aprovisionamiento de combustibles (fig. 8). En Utica en la fase romana imperial el olivo es la principal especie determinada por la antracología, lo que parece indicar que los olivos se han apropiado de la mayor parte de las llanuras de Utica (Rodríguez-Ariza et al. 2020), quizás porque aquí el proceso de introducción del olivo se realizó antes, aunque con una importancia moderada durante los tiempos de los fenicios hacia el siglo IV a.C. (Van Zeist y Bottema 1983, Bottema y Van Zeiss 1985, Van Zeist et al. 2001).
Sin embargo, esta relativa poca disminución de la vegetación climácica en Cástulo (fig. 8) enmascara el cambio cualitativo de la vegetación. La disminución en casi el 30\% de la encina/coscoja y la desaparición del madroño, están compensadas por la aparición y presencia importante del pino carrasco (en torno al 15-20\%), especie que se desarrollaría en zonas marginales o lugares donde el encinar se haya destruido o degradado. Esto aboga por un cambio de la vegetación del entorno más importante de lo que los datos cuantitativos reflejan.

Los resultados antracológicos, con los grupos de vegetación que se han constatado (fig. 8), definen la existencia de 3 áreas de proveniencia de la leña y madera utilizada en Cástulo: la primera del entorno del río Guadalimar, la segunda del entorno del poblado y la tercera de los campos de cultivo (fig. 2). La explotación de cada una de estas áreas estaría en función de las necesidades y el uso que se le iban a dar a la leña y madera utilizadas. La principal área representada es la de la vegetación del entorno, señalando una recogida de la leña más o menos cercana y, posiblemente también, a que el aprovisionamiento de leña estaría realizado por grupos o personas específicas que se dedican de manera profesional, los cuales no utilizan maderas blandas, como es el caso de las especies de ribera, ni restos de podas de los árboles frutales, salvo el caso del olivo a partir de su implantación en el siglo I d.C. Igualmente, las áreas de explotación del bosque estarían delimitadas y entre ellas parece que la ripisilva gozaba de cierto control o bien, la extensión de los campos de cultivo en el valle del Guadalimar ocupaba gran parte del área próxima al curso del agua, dejando muy reducida el área para su desarrollo. 
Hasta hace muy pocos años, se venía defendiendo que la Alta Andalucía (tanto el Alto Guadalquivir como la Vega de Granada) eran zonas romanas en la que la producción de aceite y la plantación de olivos eran fenómenos residuales, en comparación con las evidencias de torcularia y sobre todo de centros de producción de ánforas Dressel 20 para el transporte marítimo de aceite, que son tan abundantes en el Guadalquivir Medio y Bajo e inexistentes en estas zonas. Buena parte de esa interpretación histórica sobre el origen del olivar se realizó a partir de prospecciones de M. Ponsich (1974, 1979, 1987), que han servido a muchos arqueólogos e historiadores como trabajos de cabecera sobre la implantación romana en la Bética. Sin embargo, desde los años 2000 se han sucedido los descubrimientos arqueológicos en estas zonas (Hidalgo et al. 2014, López y Buzón 2014, Serrano 2004, Rodríguez et al. 2014, Rodríguez et al. 2014), que han permitido demostrar que la Alta Andalucía no solo no fue una zona secundaria en la producción de aceite, sino que incluso pudo ser un foco de desarrollo de este cultivo a partir de mediados del siglo I a.C.

El descubrimiento y excavación de varios centros de producción a escala industrial, probablemente los mayores de la Península, como Cuétara (Jaén) (Serrano 2004) y Los Robles (Jaén) (López y Buzón 2014, Serrano et al. 2011, Serrano 2014), con sistemas de prensado complejos y de gran capacidad, significó una revolución en la forma de producir enormes cantidades de aceite. Para esa producción fue necesario plantar una ingente cantidad de olivos. Los datos procedentes de sitios como la Zona Arqueológica de Marroquíes Bajos o la cercana Puente Tablas (Rodríguez-Ariza 2017) demuestran que, en el contexto del ibérico final, entre los siglos II y mediados del I a.C., no existen olivos, pero que súbitamente, hacia el cambio de Era, aparecen instalaciones de prensado como Cuétara, un torcularium con una batería de seis prensas de gran capacidad, con contrapesos de más de $4000 \mathrm{~kg}$. Ello significa que en el interludio de la segunda mitad del siglo I a.C., se produjo una plantación masiva de olivos que va a modificar los entornos de los asentamientos, tal como observamos en Cástulo.

A partir de estudios antracológicos de varios yacimientos arqueológicos del I milenio de la región andaluza se ha realizado una síntesis de la dinámica vegetal durante el I milenio a.C. en el Sur de la península ibérica (Rodríguez-Ariza 2014, 2017). Se observa una parecida coincidencia de cambio en el medio ambiente y de transformación sociocultural y económica. Este cambio está producido por la acción antrópica sobre los suelos más fértiles, como consecuencia de la extensión e intensificación de la producción agrícola: primero, con los cereales que se vienen cultivando desde el Neolítico; después, con la vid que se introduce en Andalucía en un momento protohistórico; y, por último, con el olivo en época romana.

\section{Agradecimientos}

Este estudio se ha realizado dentro del Proyecto de Investigación: Cástulo: investigación arqueométrica y transferencia social. (HAR2016-74917-R). Ministerio de Economía y Competitividad. 2016-2019. La autora agradece la colaboración prestada por Carmen Pradas en la identificación de las muestras. A Francisco Arias y Marcelo Castro (Conjunto Arqueológico de Cástulo, Junta de Andalucía) su buena disposición y la cartografía del yacimiento y a Eva Montes, Bautista Ceprían y Daniel Ureña el control y realización de la flotación del sedimento.

\section{BIBLIOGRAFÍA}

Barba, V.; Fernández, A. y Jiménez, Y. (2015): "La muralla de Cástulo y la Puerta de los Leones", en A. Ruiz y M. Molinos, M (eds.), Jaén, tierra ibera 40 años de investigación y transferencia: 305-321. Jaén, Universidad de Jaén.

Badal, E.; Bernabeu, J. y Vernet, J.L. (1994): "Vegetation changes and human action from the Neolithic to the Bronze Age (7000-4000 BP) in Alicante, Spain, based on charcoal analysis". Vegetation History and Archaeobotany 3: 155-166.

Blázquez, J.M. (1975): Cástulo I. Acta Arqueológica Hispánica 8. Madrid.

Blázquez, J.M. (1979): Cástulo II. Madrid. Ministerio de Cultura, Dirección General del Patrimonio Artístico, Archivos y Museos, Subdirección General de Arqueología.

Blázquez, J. M. (1981): Cástulo III. Excavaciones Arqueológicas en España 117. Madrid, Ministerio de Cultura.

Blázquez, J.M.; Contreras, R. y Urruela, J.J. (1984): Cástulo IV. Excavaciones Arqueológicas en España 131. Madrid, Ministerio de Cultura.

Blázquez, J.M.; García-Gelabert, M.P. y López Pardo, F. (1985): Cástulo V. Excavaciones Arqueológicas en España 140. Madrid, Ministerio de Cultura, Dirección General de Bellas Artes y Archivos, Subdirección General de Arqueología y Etnografía. 
Blázquez, J.M. y García-Gelabert, M.P. (1992): "Secuencia histórica de Cástulo (Linares, Jaén)". Estudios de arqueología ibérica y romana. Homenaje a Enrique Pla Ballester, Trabajos Varios del Servicio de Investigación Prehistórica 89: 391-396.

Blázquez, J.M. y García-Gelabert, M.P. (1994): Cástulo: ciudad ibero-romana. Madrid. Ed. Istmo.

Chabal, L. (1992): "La représentativité paléoecologique des charbons de bois archéologiques issus du bois de feu". Bulletin de la Societe Botanique de France-Lettres Botaniques 139: 213-236.

Ceprián, B.; Expósito, D.; Soto, M. y López, M.P. (2016): "Hallazgos monetarios para el conocimiento de la secuencia estratigráfica en Cástulo", en Actas del XV Congreso Nacional de Numismática: 999-1024. Madrid (2014), Madrid, RCM-FNMT.

Duque, D. (2004): La gestión del paisaje vegetal en la Prehistoria Reciente y Protohistoria en la Cuenca Media del Guadiana a partir de la Antracologia. 2004. Tesis Doctoral. Universidad de Extremadura.

Figueiral, I. (1993): "Charcoal analysis and the vegetational evolution of North-West Portugal". Oxford Journal of Archaeology 12: 209-222. https://doi. org/10.1111/j.1468-0092.1993.tb00292.x.

Figueiral, I. (1996): "Wood resources in north-west Portugal: their availability and use from the late Bronze Age to the Roman period". Vegetation History and Archaeobotany 5: 121-129. https://doi. org/10.1007/BF00189442.

García, M.S. y Grau, E. (2005): “Aprovechamiento de los recursos leñosos en la fase protohistórica de Punta de los Gavilanes (Mazarrón, Murcia)". Anales de Prehistoria y Arqueología 21: 51-68.

Hidalgo, R.; Buzón, M. y Carrillo, J.R. (2014): “Las villas romanas de Andalucía: Novedades y últimos hallazgos. Presentación". Romvla 12: 7-18.

López, A. y Buzón, M. (2014): "La Villa Romana de Córtijo de Los Robles (Jaén)". Romvla 12-13: 379414

Pérez, C. (2014): “Depósitos arqueológicos, sucesión estratigráfica y fases de ocupación". Siete esquinas 6: 61-72.

Marston, J.M. (2009): "Modeling wood acquisition strategies from archaeological charcoal remains". Journal of Archaeological Science 36: 2192-2200. https://doi.org/ 10.1016/j.jas.2009.06.002.

Ponsich, M. (1974): Implantation rurale antique sur le bas-Guadalquivir. Vol. I. París, D. de Boccard.

Ponsich, M. (1979): Implantation rurale antique sur le Bas-Guadalquivir. Tomo II. Publications de la Casa de Velázquez, serie Archeologie. Madrid, Diffusion De Boccard.

Ponsich, M. (1987): Implantation rurale antique sur le Bas-Guadalquivir. Tomo III. Publications de la Casa de Velázquez, serie Archeologie. Madrid, Diffusion De Boccard.

Rivas-Martínez, S. (1987): Memoria del mapa de Series de vegetación de España 1:400.000. Madrid, ICONA.

Rodríguez, A.; García-Consuegra, J.M.; Rodríguez, J.; Pérez, M. y Marín, P. (2014): “La Villa Bajoimperial y Tardo Antigua de Los Mondragones (Granada)". Cuadernos de Prehistoria y Arqueología de la Universidad de Granada 24: 459-496.

Rodríguez, A.; García-Consuegra, J.M.; Rodríguez, J., y Pérez, M.J. (2014): "La villa romana de Los Mondragones (Granada): Un nuevo yacimiento arqueológico en el entorno de Iliberis". Romvla 1213: 475-501

Rodríguez-Ariza, M.O. (2011): "Evolución y uso de la vegetación durante la Prehistoria en el Alto Guadalquivir". Menga 02: 34-57.

Rodríguez-Ariza, M.O. (2014): "Intensificación agraria, arboricultura y vegetación durante el I milenio a.n.e. en Andalucía a partir de la Antracología". Cuadernos de Prehistoria y Arqueología de la Universidad de Granada: 333-358.

Rodríguez-Ariza, M.O. (2017): “Use, management and spatial analysis of wood resources in the iberian oppidum of Puente Tablas (Jaén, Spain)". Estudos do Quaternário/Quaternary Studies 16: 41-53.

Rodríguez-Ariza, M.O. y Montes Moya, E. (2005): "On the origin and domestication of Olea europaea L. (olive) in Andalucía, Spain, based on the biogeographical distribution of its finds", en R. Buxó, S. Jacomet y F. Bitmann (eds.), Interaction between Man and Plants. New Progress in Archaeobotanical Research. Vegetation, History and Archaeobotany 14: 551-561.

Rodríguez-Ariza, M.O.; López, J.L.; Ben Jerbania, I.; Mederos, A.; Ferjaoui, A.; Martínez, V.; Pardo, C.A.; Sánchez, A.; Khalfali, W. y Jendoubi, K. (2020): "Long term human impact and forest management in the phoenician and roman city of Utica (Tunisia) (900 bc-500 ad)", The Holocene 31: 1-32.

Rubiales, J.M.; Hernández, L.; Romero, F. y Sanz, C. (2011): "The use of forest of resources in central Iberia during the Late Iron Age. Insights from the wood charcoal analysis of Pintia, a Vaccaean 
oppidum". Journal of Archaeological Science 38: 1-10. https://doi.org/10.1016/j.jas.2010.07.004.

Sánchez, A.; Parras, D; Montes, E.; Castro, M.; Tuñón, J.A.; Rodríguez-Ariza, M.O.; Montejo, M.; Ceprián, B.; Amate, P. y Vandenabeele, P. (2020): "Cástulo: investigación arqueométrica y transferencia social”. PH: Boletín del Instituto Andaluz del Patrimonio Histórico, 99: 44-64.

Schweingruber, F. 1990. Anatomie europäischer Hölzer. Berna-Stuttgart, Paul Haupt AG Verlag.

Schweingruber, F.H.; Börner, A. y Schulze, E.D. (2011): Atlas of Stem Anatomy in Herbs, Shrubs. Volumen 1. Berlín-Heidelberg, Springer Science \& Business Media. https://doi.org/10.10007/978-3642-11638-4.

Schweingruber, F.H.; Börner, A. y Schulze, E.D. (2013): Atlas of Stem Anatomy in Herbs, Shrubs. Volume 2. Berlín-Heidelberg, Springer Verlag \& Business Media. https://doi.org/10.10007/978-3642-20435-7.

Serrano, J.L. (2004): "Consideraciones sobre la producción del aceite en el Alto Guadalquivir: el caso de Aurgi (Jaén)". Archivo Español de Arqueología 77: 159-176. https://doi.org/10.3989/aespa.2004. v77.95.

Soto, M.; Expósito, D.; Ceprián, B. y López, M.P. (2018): "Avance cronológico del Santuario de
Torre Alba (Cástulo): las cerámicas del estrato 1879", en H. Uroz y A. Ribera (eds.): Cultura material romana en la Hispania republicana I: 349-358.

Tornero, A. (1998): "Restos arqueológicos hallados en el área de influencia de Cástulo”, en J. Mangas y J. Alvar (coord.): Homenaje a José María Blázquez, Vol. 5: 393-398. Madrid, Ediciones Clásicas.

Torres, J.A.; Valle, F.; Pinto, C.; García-Fuentes, A.; Salazar, C. y Cano, E. (2002): “Arbutus unedo L. communities in southern Iberian Peninsula mountains". Plant Ecology 160: 207-223. https://doi. org/10.1023/A:1015864821706.

Tudela, A.R.; Ruiz, M.J y Liétor, J. (2014): “Aproximación a la fauna malacológica del yacimiento arqueológico de Cástulo (Linares, Jaén, España)". Siete Esquinas 6: 21-27.

Varo, J.; Guerra, J. y Gil, J. A. (1977): "Estudio Briológico de la Sierra del Torcal de Antequera (Málaga)". Acta Botánica Malacitana 3: 35-62.

Vernet, J.L. (Coord.) (2001) : Guide d'identification des charbons de bois préhistoriques et récents. $\mathrm{Pa}-$ rís, CNRS Editions.

Vila, S. (2018): L'explotació dels recursos vegetals a la plana occidental catalana durant la protohistòria a partir de l'anàlisi antracològica (III-I mil·lenni). Tesis doctoral, Universidad de Lleida. 